\title{
Priorities in Global Assistance for Health, AIDS, and Population
}

\author{
LANDIS MACKELLAR
}

IN RECENT YEARS, the possibility of a deadly influenza pandemic, the episode of severe acute respiratory syndrome (SARS), concerns over bioterrorism, the HIV/AIDS epidemic, and no doubt other events have increased the importance with which global public health is viewed. Even without an "event," though, health has a strong claim on our attention, for humanitarian reasons if none other. The World Bank's 1993 World Development Report, a flagship document in the field of health and development, identified a minimum care package that would cost a mere US\$12 per capita (in 1990 terms) to deliver. The World Health Organization (WHO) estimates that the cost of an essential health care package in low-income countries is $\$ 12$ per capita, and in middle-income countries $\$ 22$ per capita. The comparison between the misery caused by poor health in the developing world and the apparently trivial sums required to improve it could not be more striking.

But is the global community willing to act? The international assistance required to finance adequate levels of health in poor countries was estimated by the WHO Commission on Macroeconomics and Health (2001) to be $\$ 27$ billion in 2007: $\$ 22$ billion for in-country programs, $\$ 3$ billion for research and development targeted at diseases of the poor, and $\$ 2$ billion in classic global public goods such as collection and analysis of epidemiological data and surveillance of infectious disease. This sum may be compared to actual spending of only about $\$ 6$ billion per year in 2001. The United Nations High Level Panel on Financing for Development, the so-called Zedillo Commission, estimated that an extra US\$7-10 billion per year in resources is required at a minimum to fight communicable diseases alone (United Nations 2001).

This enormous gap between needs and current spending suggests that, however innovative the funding strategies devised, Zedillo- and WHO-size goals are unlikely to be met in anything approaching their entirety. When needs vastly outstrip resources, priority setting is crucial. Aggregate trends 
in official development assistance for health, AIDS, and population have been documented (OECD 2001: 139-150; Development Assistance Committee-UNAIDS 2004 for HIV/AIDS), and the question of how disease priorities ought to be set has received a great deal of attention. Apart from analysis by Shiffman (2004) on infectious disease, however, little work has been done on how they actually are set.

This article consists of three parts. The first examines international assistance for health, AIDS, and population for two years, 1993 and 2003. This period is roughly framed by two landmark events in international health policy: publication in 1993 of the aforementioned World Development Report, subtitled Investing in Health; and publication at the end of 2001 of the Report of the WHO Commission on Macroeconomics and Health. During this decade, health emerged as a key strategic sector in development, and links between health and poverty were increasingly recognized.

The second part, building on the approach that Shiffman has applied to infectious disease, compares development assistance for health, AIDS, and population in various intervention categories to the burden of disease in the corresponding disease categories. The question is how closely development assistance allocations match the burden of disease and, where they do not, what the explanation might be.

The third part summarizes an ad hoc but innovative attempt to assess stated health priorities in poor countries and the extent to which patterns of official development assistance conform to them. While concerns have long been expressed that international assistance may not reflect priorities in recipient countries (Maizels and Nissanke 1984), this concern has lately been heightened as the global public good perspective on health is increasingly used to justify support for spending (Sagasti and Bezanson 2001; Sandler and Arce 2001). It also reflects the conviction, expressed, for example, at the March 2005 High Level Forum on Aid Effectiveness in Paris, that aid is effective only if it is aligned with country priorities.

\section{Trends in aggregate development assistance and in assistance for health and population}

In view of the gap between resources and needs, a range of innovative approaches to health financing has been proposed (Atkinson 2003; Reisen 2004; Stansfield et al. 2001). Innovative public-private partnerships are underway in the form of the Global Fund to Fight AIDS, Tuberculosis and Malaria; the International AIDS Vaccine Initiative; the US President's Emergency Program for AIDS Relief; the Global Alliance for Vaccines and Immunization; Stop TB; and Roll Back Malaria. However, the bulk of resources for these and other initiatives still comes from the traditional source: donor-country governments as represented in the Development Assistance Committee and, to a lesser extent, multilateral institutions such as the World 
Bank. ${ }^{1}$ The primary vehicle for in-country projects remains official development assistance; therefore, trends in such assistance should be a reasonable measure of global priorities.

\section{Aggregate development assistance}

The standard source for data on official development assistance is the Creditor Reporter System database maintained by the Development Assistance Committee. The data employed in this article were compiled by aggregating, for 1993 and 2003 (the most recent year available), the finest-grained information available in the database. ${ }^{2}$ In an effort to be comprehensive, I include all donors, all recipients, and all types of assistance, including loans (fairly few and far between in assistance for health, AIDS, and population).

The limitations of the Creditor Reporter System database are well known. The Organization for Economic Co-operation and Development has estimated that it is only about 75 to 80 percent complete for the 1990s (OECD 2001: 140). Data are for commitments, not actual disbursements, which may be significantly lower. Other problems include the fact that classification in the database is all-or-nothing: for example, a reproductive health and family planning project that includes a substantial HIV/AIDS component will not appear in the HIV/AIDS category. The database does not cover private foundations and nongovernmental organizations (NGOs) and is incomplete for UN agencies and the European Commission through its European Development Fund. Nevertheless, the Creditor Reporting System data continue to be widely used to identify major trends in and characteristics of development assistance.

In the Development Assistance Committee classification system, health activities fall under the category "Social infrastructure and services." They are further subdivided into "General health" (health policy and administrative management, medical education/training, medical research, and medical services) and "Basic health" (basic health care, basic health infrastructure, basic nutrition, infectious disease control, health education, and health personnel development). Population activities encompass population policy and administrative management, reproductive health care, family planning, sexually transmitted disease (STD) control including HIV/AIDS, and personnel development for population and reproductive health. In fact, HIV/ AIDS accounts for almost all assistance for STD control.

Areas of development assistance not directly related to health, AIDS, and population are other social infrastructure and services (aid to the education sector, water and sanitation projects, and projects aimed at encouraging good governance and the development of civil society), economic infrastructure (banking, transport, etc.), sector aid (agriculture, industry, etc.), commodity and general programmatic assistance (chiefly nonemergency food aid, structural adjustment funds, and general budget/balance-of-payments 
support), multisector assistance (women in development, environment, and rural development), and actions related to debt (debt forgiveness, rescheduling, etc.). Some of these, such as water and sanitation and nutrition, clearly have health benefits; indeed, one could argue that any assistance that accelerates development is bound to benefit health. In this article, however, I consider only interventions explicitly assigned to the health category.

Development assistance for health, AIDS, and population, 1993 and 2003

As shown in Table 1, official development assistance for health, AIDS, and population is estimated to have more than doubled, from $\$ 3,107$ million in 1993 to $\$ 6,719$ million in 2003 (these and all other figures given here are in 2002 prices). The implied growth rate of 8.0 percent per annum confirms the rapid expansion in this sector. Total development assistance grew more slowly, by 5.9 percent per annum over the period, so the share devoted to health, AIDS, and population increased from 5.5 percent to 6.7 percent of total development assistance. While the share of assistance devoted to health is only one measure of priority, this is evidence that increasing attention to the health sector in development is being backed up with development assistance resources. Many of these resources, however, were devoted to the unforeseen HIV/AIDS crisis. In 1993, HIV/AIDS represented an insignificant 0.1 percent of total development assistance; in 2003, it represented 1.8 percent-an increase at a rate of 36.7 percent per annum. Health and population minus HIV/AIDS actually lost share in total

TABLE 1 Official development assistance for health, AIDS, and population, US\$ million (2002 prices)

\begin{tabular}{lrrr}
\hline & $\mathbf{1 9 9 3}$ & $\mathbf{2 0 0 3}$ & $\begin{array}{r}\text { Growth rate } \\
\text { (percent per } \\
\text { annum) }\end{array}$ \\
\hline $\begin{array}{l}\text { Health, AIDS, and population } \\
\quad \text { AIDS }\end{array}$ & 3,107 & 6,719 & 8.0 \\
$\quad \begin{array}{l}\text { Health and population } \\
\text { Total development assistance }\end{array}$ & 3,030 & 1,754 & 36.7 \\
$\begin{array}{l}\text { Health, AIDS, and population share in } \\
\text { total development assistance (percent) } \\
\quad \begin{array}{l}\text { AIDS share in total development } \\
\text { assistance (percent) }\end{array}\end{array}$ & 56,451 & 9,965 & 5.1 \\
$\quad \begin{array}{l}\text { Health and population share in total } \\
\text { development assistance (percent) }\end{array}$ & 5.5 & & 5.9 \\
\hline
\end{tabular}

SOURCE: Creditor Reporting System. 
development assistance over the decade, from 5.4 percent in 1993 to 5.0 percent in 2003.

Table 2 focuses on those health, AIDS, and population intervention subsectors most broadly identified as "pro-poor." This list consists of "Basic health" as defined by the Development Assistance Committee, plus reproductive health and family planning and STDs including HIV/AIDS.

Taken together, the pro-poor subsectors experienced an increase in share between 1993 and 2003, from 3.3 percent to 4.6 percent of total official development assistance and from 59.7 percent to 68.1 percent of development assistance for health, AIDS, and population. Once the category HIV/ AIDS is removed, however, the share of the remaining pro-poor subsectors declined from 3.1 percent to 2.8 percent of total development assistance and from 57.2 percent to 42.0 percent of assistance for health, AIDS, and population. ${ }^{3}$ Removing HIV/AIDS from the calculations reveals both that health lost share of total development assistance and that assistance for health, AIDS, and population aid became less pro-poor over the decade.

The only one of the non-HIV/AIDS subsectors in Table 2 that experienced an increase in share was infectious disease control, rising from 0.2 percent to 0.7 percent of total official development assistance and from 3.5 percent to 10.2 percent of assistance for health, AIDS, and population. Because infectious disease control is a classic public good, this increase in share may be evidence of the growing importance of the global public good per-

TABLE 2 Health, AIDS, and population intervention subsector shares in official development assistance, 1993 and 2003

\begin{tabular}{|c|c|c|c|c|}
\hline \multirow[b]{3}{*}{ Intervention subsector } & \multicolumn{4}{|c|}{ Share of intervention subsector in } \\
\hline & \multicolumn{2}{|c|}{$\begin{array}{l}\text { All development } \\
\text { assistance }\end{array}$} & \multicolumn{2}{|c|}{$\begin{array}{l}\text { Health, AIDS, } \\
\text { and population } \\
\text { development } \\
\text { assistance }\end{array}$} \\
\hline & 1993 & 2003 & 1993 & 2003 \\
\hline Basic health care and infrastructure & 0.8 & 0.8 & 14.1 & 12.2 \\
\hline $\begin{array}{l}\text { Health education and personnel } \\
\text { development }\end{array}$ & 0.3 & 0.1 & 6.2 & 0.8 \\
\hline Basic nutrition & 0.6 & 0.2 & 10.9 & 2.8 \\
\hline Infectious disease control (excl. HIV/AIDS) & 0.2 & 0.7 & 3.5 & 10.2 \\
\hline Reproductive health and family planning & 1.2 & 1.1 & 22.5 & 16.0 \\
\hline $\begin{array}{l}\text { Total, pro-poor subsectors excl. STDS } \\
\text { and HIV/AIDS }\end{array}$ & 3.1 & 2.8 & 57.2 & 42.0 \\
\hline STDs incl. HIV/AIDS & 0.1 & 1.8 & 2.5 & 26.1 \\
\hline $\begin{array}{l}\text { Grand total, pro-poor health, AIDS, and } \\
\text { population subsectors }\end{array}$ & 3.3 & 4.6 & 59.7 & 68.1 \\
\hline
\end{tabular}

SOURCE: Creditor Reporting System. 
spective on health. However, many other factors, such as growing realization of links between infectious disease and development and increased appreciation of cost-effective responses such as anti-mosquito bed nets, could also be explanations.

While disaggregated data are not shown in Table 2, similar observations can be made for countries classified as "least-income" by the Development Assistance Committee. In these countries, development assistance for health, AIDS, and population increased from 5.9 percent to 7.2 percent of total assistance; but once HIV/AIDS is removed, health and population experienced a decline in share, from 5.6 percent to 4.6 percent. Development assistance in the pro-poor, non-HIV/AIDS subsectors declined from 3.2 percent to 2.4 percent of total development assistance and from 54.8 percent to 36.3 percent of assistance for health, AIDS, and population. The share of assistance for HIV/AIDS increased from 0.2 percent to 2.6 percent of total development assistance and from 4.3 percent to 36.3 percent of assistance for health, AIDS, and population. Thus, while the pro-poor subsectors taken as a whole experienced an increase from 3.2 percent to 5.0 percent of total official development assistance and from 54.8 percent to 70.0 percent of health, AIDS, and population assistance, it was HIV/AIDS that accounted for this increase. Infectious disease control again stands out, however, as a subsector that gained share, from 0.2 percent to 0.4 percent of total development assistance and from 2.7 percent to 5.0 percent of assistance for health, AIDS, and population.

To summarize, then, over a decade during which health became a major component of development strategy and links between health and poverty were increasingly recognized, health and population apart from HIV/AIDS actually lost share in total official development assistance. Even more striking, with the exception of HIV/AIDS, subsectors of health, AIDS, and population generally considered pro-poor also lost weight. These trends are observed not only for low- and middle-income countries as a whole, but also for the subset of least-income countries.

\section{Health and population assistance and the burden of disease}

Priority setting is particularly crucial when available resources fall far short of needs. A great deal of normative work has been devoted to how international disease control priorities should be set. The flagship project in this area, the WHO-World Bank-US National Institutes of Health Disease Control Priorities Project, emphasizes the burden of disease as measured in disabilityadjusted life years. The Global Forum for Health Research (2004) has proposed a framework in which health research and development priorities should be set according to reduction in the burden of disease per dollar spent, the 
determinants of the burden of disease, impact on equity, the scientific probability of success, feasibility, and contribution to capacity building.

Much less attention has been given to the equally important question of how global disease priorities are actually set. An exception to this is ongoing work by Shiffman (2004), who examines donor priorities in the area of infectious disease and concludes that considerations include not only the burden of disease, but also the speed of spread, the ability of poor countries to cope on their own, the existence of cost-effective interventions, the characteristics of the victims of disease, the prevalence and risk of infection in donor countries, and other political and economic factors. This section extends the work of Shiffman to cover all forms of disease, not just infectious disease. Following him, I compare data on health interventions from the Creditor Reporter System (CRS) database with WHO data on the burden of disease. I conclude that the burden of disease as conventionally measured can explain only part of health priorities as revealed by patterns of assistance.

The burden of disease has many dimensions: years of life lost due to premature death, physical suffering due to pain and disability, economic opportunity costs, social stigma, and so on. No single measure can capture all these aspects; however, health policymakers have generally accepted disability-adjusted life years (DALYs) lost to given disease categories as the best comprehensive measure of the burden of disease. One DALY represents a single lost year of healthy life, and the sum of DALYs lost to all causes can be interpreted as the gap between the actual health situation and an ideal world in which everyone lives disease- and disability-free to an advanced age (age 80 for men and 82.5 for women, according to the convention used by WHO). DALYs lost to a given disease category divided by total DALYs lost is a measure of the importance of that disease category relative to all diseases combined. ${ }^{4}$

Column 1 in Table 3 contains the estimated burden of disease (in DALYs) by major disease category for the year 2001. Four of these disease categories are directly comparable to development assistance intervention subsectors in the database of the Creditor Reporter System. These disease categories are

- Infectious diseases excluding HIV/AIDS and other STDs. This category, accounting for 23.6 percent of the total burden of disease in 2001, corresponds to "infectious disease control" in the CRS database.

-STDs including HIV/AIDS, accounting for 5.8 percent of the total burden of disease, is directly comparable to the same category in the CRS database. Readers are sometimes surprised by the modest share of DALYs accounted for by HIV/AIDS, but this is the result of the very large number of life years lost to other conditions such as malaria and respiratory infections.

- Maternal health and perinatal conditions; this category corresponds to "reproductive health care" and, because of the important role of child 
TABLE 3 Burden of disease in low- and middle-income countries and shares of development assistance, early $2000 \mathrm{~s}$

\begin{tabular}{|c|c|c|c|c|}
\hline \multirow[b]{2}{*}{ Disease category } & \multirow[b]{2}{*}{$\begin{array}{l}\text { DALYs } \\
\text { lost, } \\
2001 \\
(000 s)\end{array}$} & \multirow[b]{2}{*}{$\begin{array}{l}\text { Share of } \\
\text { total } \\
\text { burden } \\
\text { of disease }\end{array}$} & \multicolumn{2}{|c|}{$\begin{array}{l}\text { Share of development } \\
\text { assistance for health, AIDS, } \\
\text { and population, } 2003\end{array}$} \\
\hline & & & $\begin{array}{l} \\
\text { Directly } \\
\text { attributable } \\
\text { inter- } \\
\text { ventions }\end{array}$ & $\begin{array}{l}\text { Directly } \\
\text { attributable } \\
\text { interventions } \\
\text { plus imputed } \\
\text { general } \\
\text { assistance } \\
\text { for health, } \\
\text { AIDS, and } \\
\text { population }\end{array}$ \\
\hline $\begin{array}{l}\text { Communicable diseases, maternal } \\
\text { health, perinatal conditions, and } \\
\text { nutritional deficiencies }\end{array}$ & 552,639 & 39.8 & 54.9 & 72.9 \\
\hline $\begin{array}{l}\text { Infectious diseases } \\
\text { (excluding STDs and HIVIAIDS) }\end{array}$ & 327,407 & 23.6 & 10.2 & 20.8 \\
\hline STDs and HIVIAIDS & 80,173 & 5.8 & 25.9 & 28.5 \\
\hline $\begin{array}{l}\text { Maternal health and perinatal } \\
\text { conditions }\end{array}$ & 115,494 & 8.3 & 16.0 & 19.8 \\
\hline Nutritional deficiencies & 29,564 & 2.1 & 2.8 & 3.8 \\
\hline Noncommunicable diseases & 678,842 & 48.9 & 0.0 & 22.1 \\
\hline Injuries & 155,945 & 11.2 & 0.0 & 5.1 \\
\hline Total burden of disease & $1,387,426$ & 100.0 & 54.9 & 100.0 \\
\hline
\end{tabular}

SOURCES: DALYs, Disease Control Priorities Project (see endnote 4); development assistance, Creditor Reporting System.

spacing, "family planning" in the CRS. It is estimated to account for 8.3 percent of the total burden of disease.

-Nutritional deficiencies, which correspond to "basic nutrition" in the CRS database. These were estimated to account for 2.8 percent of the total burden of disease.

Noncommunicable diseases are completely absent from the category of directly attributable interventions shown in Column 3 of Table 3, as are injuries, because interventions to address these areas are not perceived to be pro-poor. ${ }^{5}$ Yet cardiovascular conditions, cancer, mental illness, diabetes, and other noncommunicable conditions are accounting for a fast-rising share of mortality and morbidity in developing countries. This trend will become pronounced as populations age, as income levels rise, and as recent increases in tobacco use make their presence felt.

Looking only at directly attributable interventions is misleading because general interventions ("policy administration and management," "basic health care," "basic health infrastructure," "medical education," etc.), amounting to 45.1 percent of all development assistance for health, AIDS, and population, also contribute to reducing the burden of disease. How to distribute general 
health expenditure across disease categories is a contentious issue. Table 3 follows one rule appealing in its simplicity, namely imputing general development assistance for health, AIDS, and population across burden-of-disease categories using shares of the total burden of disease (Column 2). For example, of the 45.1 percent of such assistance that cannot be directly identified by disease intervention, I impute 5.8 percent to STDs including HIV/AIDS, 8.3 percent to maternal and reproductive health, and so on.

The most striking fact revealed by Table 3 is that HIV/AIDS is being allocated a much higher share of official development assistance than can be explained by its share in the burden of disease. STDs including HIV/AIDS accounted for 5.8 percent of the burden of disease in 2001, but for 25.9 percent of assistance for health, AIDS, and population in 2003, or 28.5 percent if my approach to imputation of general health assistance is accepted. Maternal and perinatal health, accounting for 8.3 percent of the burden of disease but for 16.0 percent of directly attributable assistance for health, population, and AIDS and 19.8 percent if general assistance is imputed, also received a share of resources higher than its share in the burden of disease. This is so despite the significant reduction in share during the 1990s that may be observed in Table 2. If only direct interventions are counted, infectious diseases apart from HIV/AIDS received far less attention than would be warranted on the basis of their share in the burden of disease: 10.2 percent of development assistance as opposed to 23.6 percent of the burden of disease. However, if general assistance is imputed, this anomaly is resolved, as infectious diseases excluding HIV/AIDS are estimated to account for 20.8 percent of assistance for health, AIDS, and population, not far out of line with their share in the burden of disease. Noncommunicable diseases and injuries are estimated to receive far less assistance than would be justified by their contribution to the burden of disease.

The data in Table 3 are plotted in Figure 1. The 45-degree line represents the locus along which each disease condition receives the same share of official development assistance as its share in the burden of disease. The discussion above has in effect compared the data points in Figure 1 with the 45-degree line. But we know, from Shiffman's work on infectious diseases, that shares of development assistance are decided on the basis of factors in addition to the burden of disease. Therefore, it is unreasonable to expect the data points in Figure 1 to rest on the 45-degree line. For this reason, I also draw a least-squares trend line through the data points. Statistical inference, let alone hypothesis testing, is not possible with so few data points, but the trend line is still useful to give an idea of the average relationship between the burden of disease as expressed in disability-adjusted life years and development assistance. HIV/AIDS, in particular, and to lesser extent maternal and reproductive health, stand out as intervention sectors that receive relatively generous allocations of assistance; nutri- 
FIGURE 1 Share of development assistance for health, AIDS, and population (including imputed general assistance for health, AIDS, and population) plotted against share of DALYs, early 2000s

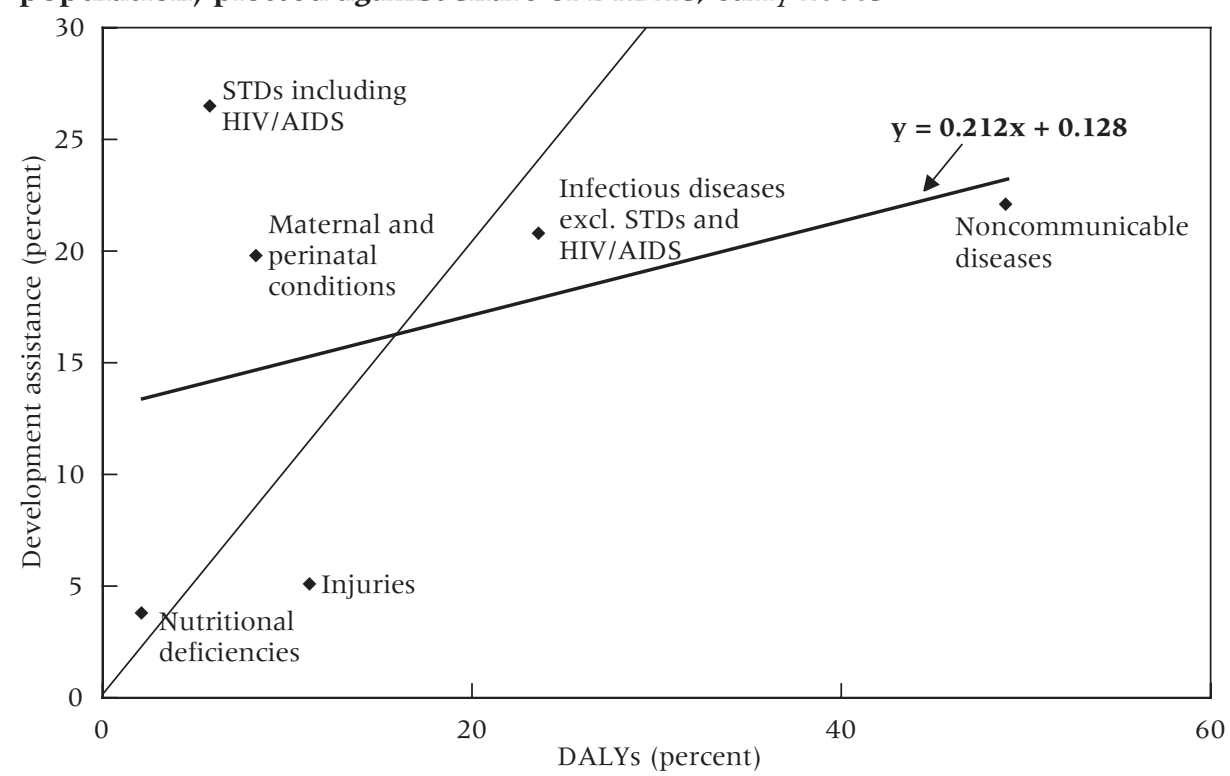

SOURCES: DALYs, Disease Control Priorities Project (see endnote 4); development assistance, Creditor Reporting System.

tion and injuries appear as sectors that receive far less support than might be expected. ${ }^{6}$

It may be argued that the least-squares line in Figure 1 is essentially meaningless and so, therefore, is lying above or below it. In this case, we might look simply at development assistance per disability-adjusted life year. These data, shown in Table 4, reveal that whether or not general assistance is imputed, HIV/AIDS receives far more dollars per DALY than any other cause. Other infectious diseases, even when assigned a share of general assistance commensurate with their large share of the burden of disease, receive a low level of assistance per DALY. By this criterion, the rising share of infectious diseases in development assistance discussed in the previous section appears to be well founded.

The main conclusion here is that health priorities as revealed by patterns of development assistance differ markedly from the priorities that might be predicted based on the burden of disease as measured in disability-adjusted life years. This conclusion broadens, to all disease categories, Shiffman's conclusion that infectious disease control priorities reflect many factors other than the burden of disease alone.

HIV/AIDS receives an allocation of resources that is very generous compared to its contribution to the total burden of disease. Yet this should not come as a surprise. HIV/AIDS advocacy groups have been very effective. 
TABLE 4 Level of development assistance in 2003 per disability-adjusted life year (US\$, 2002 prices)

\begin{tabular}{|c|c|c|}
\hline & $\begin{array}{l}\text { Development } \\
\text { assistance per } \\
\text { DALY (directly } \\
\text { attributable inter- } \\
\text { ventions only) }\end{array}$ & $\begin{array}{l}\text { Development } \\
\text { assistance per } \\
\text { DALY (including } \\
\text { imputed general } \\
\text { assistance for } \\
\text { health, AIDS, } \\
\text { and population) }\end{array}$ \\
\hline Infectious disease (excl. STDs and HIV/AIDS) & 2.09 & 4.27 \\
\hline STDs and HIV/AIDS & 21.88 & 24.06 \\
\hline Maternal and perinatal conditions & 9.29 & 11.46 \\
\hline Nutritional deficiencies & 6.30 & 8.45 \\
\hline Noncommunicable disease & 0.00 & 2.18 \\
\hline Injuries & 0.00 & 2.17 \\
\hline
\end{tabular}

SOURCE: DALYs, Disease Control Priorities Project (see endnote 4); development assistance, Creditor Reporting System.

The virus is spreading rapidly in many parts of the world, and current aid allocations may reflect the conviction that, if not addressed now, the epidemic will be even worse in the future. The fear factor, the concern in donor countries that the epidemic may affect their own populations if not controlled elsewhere, cannot be ignored. In those countries that are most severely affected, governments are entirely unable to cope with the consequences of the epidemic. If uncontrolled, the epidemic has the potential to undermine all health activities in some countries-indeed, all development (Roberts 2003: 80-81). Thus, based largely on the availability of cost-effective means of HIV/AIDS prevention, the Copenhagen Consensus of economists recently rated slowing the spread of HIV/AIDS as the highest-priority intervention for sustainable development (Lomborg 2004).

The special status given to HIV/AIDS has been made explicit by the WHO Commission on Macroeconomics and Health, which in its Key Findings termed the epidemic a "distinct and unparalleled catastrophe" requiring "special consideration." This view has been bolstered by the joint World Bank-International Monetary Fund Development Committee (World Bank 2003: 9-10), which in a survey of global public goods identified HIV/AIDS control as an area "especially" in need of attention and action.

A word is in order on disease categories apart from HIV/AIDS. Maternal and reproductive health interventions are also attractive to donors for a number of reasons: they are typically highly cost-effective; maternal and reproductive health is of concern to a group widely perceived as vulnerable (women, children, and adolescents); and an effective global advocacy community is in place. Poor nutrition, however, also disproportionately affects children (and women), there are cost-effective interventions, and recent work suggests that poor nutrition is enormously important if attention is 
given to its role as a co-factor in infectious disease prevention (Mason et al. 2003). Yet this category receives little support.

\section{Does development assistance for health and population reflect the priorities of poor countries?}

\section{The institutional context}

The "Monterrey Consensus," which now forms the basis for all development assistance, rests on three pillars: "country ownership," a comprehensive and long-term approach, and partnership (World Bank 2003: 2). The Monterrey Consensus provides the framework within which to pursue the Millennium Development Goals adopted by 189 states. ${ }^{7}$ Developed countries and the development agencies will, in return for poor countries' efforts to attain the Millennium Development Goals, take primary responsibility to establish a global partnership for development.

The Millennium Development Goals emerged from widespread dissatisfaction with the effectiveness of aid and reflected insistence on a "results focus," especially improved monitoring and evaluation (Devaradjan et al. 2002: 2). The cornerstone of the process for achieving the goals is the elaboration, in all low-income countries, of a Poverty Reduction Strategy Paper (World Bank nd: 7 and 8; World Bank 2002: 5); this process, in turn, is meant to encourage countries to adopt a long-term vision that takes poverty issues explicitly into account and reflects the views of all stakeholders. Poverty-reduction strategies are meant to be country-driven ("ownership" again), results-oriented, and participatory, that is, reflect input of civil society and the private sector (Christiansen and Hovland 2003: 3). Countries are meant to prioritize the Millennium Development Goals in accordance with their long-term vision of development needs. Donors, as evidenced by the March 2005 Paris Declaration on Aid Effectiveness, are committed to "aligning" their assistance with country priorities.

Poor countries' health priorities and development assistance

There is no clear-cut way to quantitatively measure government health priorities in poor countries. However, the same lack of information is no longer a constraint when it comes to qualitative indicators of government health priorities. Systematic evidence on the role of health in countries' povertyreduction strategy papers is now available in a WHO database. ${ }^{8}$ This database contains analytical findings on how health and poverty issues were dealt with in 36 poverty-reduction strategies drafted between 2000 and 2003.

As described in detail elsewhere (MacKellar 2005), I summarized information available in the WHO database for three disease categories: in- 
fectious diseases excluding HIV/AIDS, HIV/AIDS, and maternal and reproductive health. To roughly quantify the degree of government priority attached to each area, I selected three criteria:

-Is the disease category explicitly identified in the country's povertyreduction strategy?

- Are proposed interventions targeted at the poor (or, in the case of HIV/AIDS, at vulnerable populations)?

- Is the strategy explicitly linked to the relevant Millennium Development Goals?

If the answer to the question was "Yes," I assigned a score of 1, if "No," a score of 0 ; summing across the three criteria, I arrived at an index of disease-category prioritization that runs from 0 to 3.

The logic behind the index is simple. Most countries, for instance, identified infectious disease as an area of concern, that is, most countries scored 1 on the first criterion. It stands to reason, however, that if a country truly ascribed a high priority to infectious disease control in its long-run development strategy, it would take the subsequent steps of targeting proposed interventions toward the poor and linking its intervention strategy to the relevant Millennium Development Goals.

Figures 2 to 7 are scatter plots of the share of three intervention subsectors in total official development assistance and in health, AIDS, and population assistance against the disease-category prioritization score. Nothing in these charts shows evidence that recipient-country disease priorities as expressed in the poverty-reduction strategies strongly affect either how much of total development assistance is devoted to the corresponding intervention subsector or how much of health, AIDS, and population assistance is devoted to it. Countries that do not prioritize infectious disease are just as likely to have received a high share of total and health, AIDS, and population assistance dedicated to infectious disease control as countries prioritizing the disease category. A number of countries that assigned no priority to HIV/AIDS received, as is sensible, little assistance in that area. However, some countries that satisfied all three criteria in the area of HIV/ AIDS received no more assistance in this area, proportionally speaking, than countries assigning less priority to the disease. The same observation holds for maternal and reproductive health.

These negative results are open to three interpretations. The first, predicated on the assumption that my disease-category prioritization scores accurately measure country priorities, is that donors do not take these priorities into account when allocating development assistance.

The second interpretation is that the ad hoc index I have calculated is unsatisfactory, that is, the disease-category prioritization scores are meaningless and their representation in Figures 2-7 is best ignored.

A third interpretation is that the scores simply measure how well countries followed the guidelines for devising poverty-reduction strategies. In other 
FIGURE 2 Infectious disease control as share of total development assistance

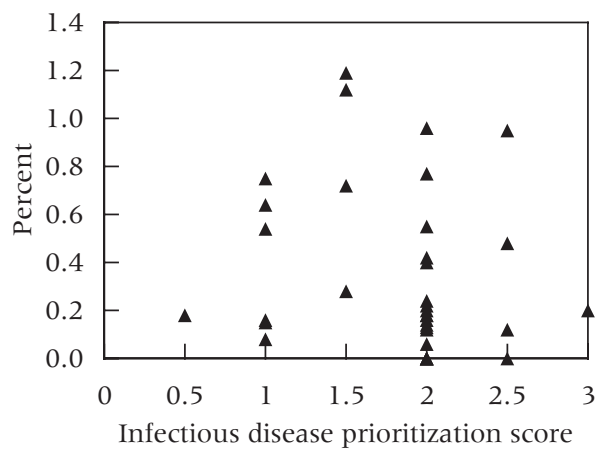

FIGURE 4 HIV/AIDS as share of total development assistance

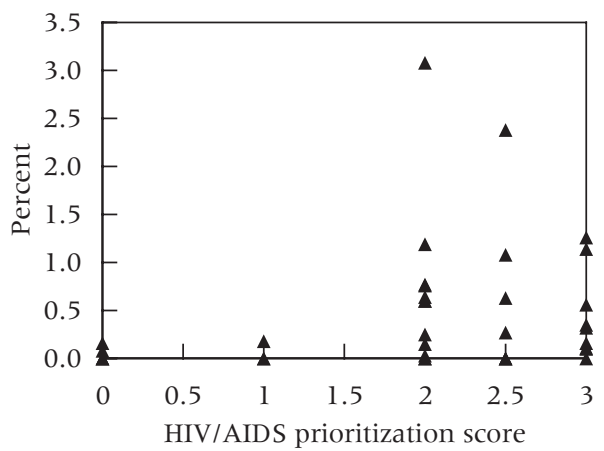

FIGURE 6 Reproductive health and family planning as share of total development assistance

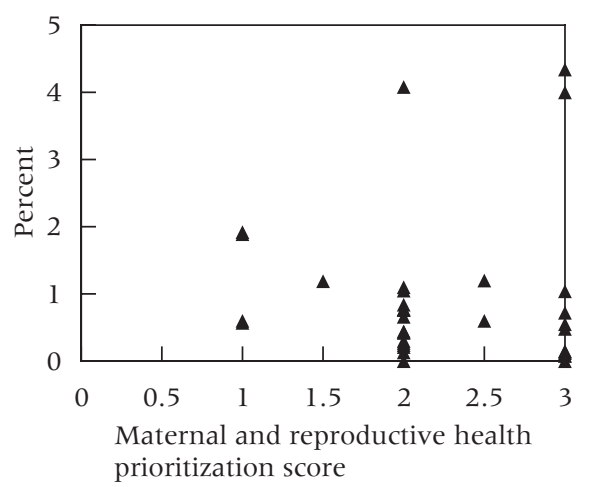

FIGURE 3 Infectious disease control as share of development assistance for health, AIDS, and population

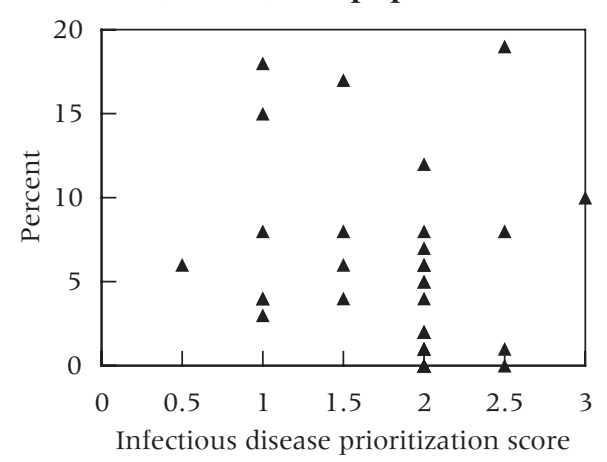

FIGURE 5 HIV/AIDS as share of development assistance for health, AIDS, and population

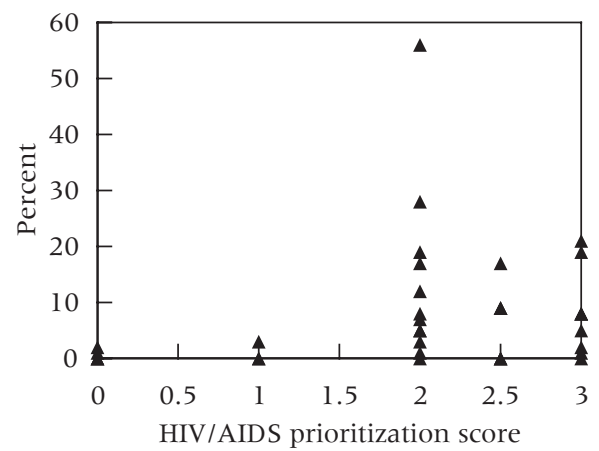

FIGURE 7 Reproductive health and family planning as share of development assistance for health, AIDS, and population

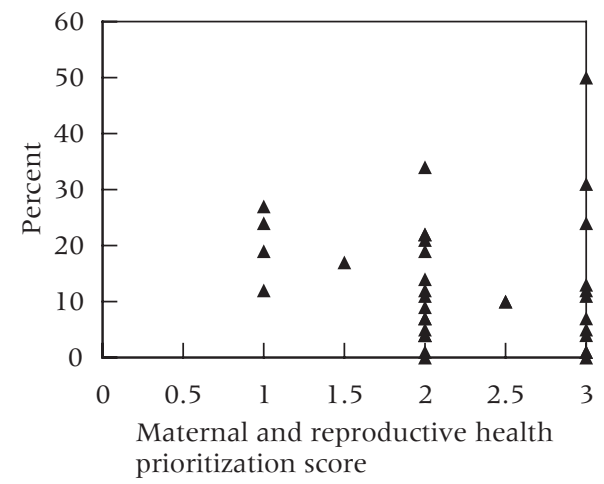

SOURCES: Prioritization scores calculated from information in WHO database (see MacKellar 2005); development assistance shares, Creditor Reporting System. 
words, the degree to which a country explicitly targeted strategies toward the poor and linked proposed interventions to the relevant Millennium Development Goals may reflect not priorities per se, but whether the country was able to produce a strategy that conformed to international standards.

In the third interpretation, donor countries seem to be more willing to allocate resources to general health policy, administration, and management, leaving it to recipient-country governments to make allocation decisions across disease categories. After all, the move from project-based approaches to sector-wide support is a vital aspect of country "ownership," and the main constraint to ownership is generally held to be country capacity. In Figures 8 and 9, I plot general health policy, administration, and management support against the average of the infectious disease, HIV/AIDS, and maternal and reproductive health prioritization scores described above. My hypothesis is that the average prioritization score serves as a proxy for country capacity. There is some evidence in favor of this interpretation: most countries receiving a high share of development assistance in the form of general support scored at least 2 on the average index. The evidence is hardly compelling, however; some countries that scored high received relatively small amounts of general health-sector assistance; some that scored low received relatively large amounts.

The evidence presented in this section is ambiguous. This in itself is cause for concern: however imperfect the index, one would expect to see at least some evidence of a relationship between the way a disease category is treated in the country strategy and the allocation of development assistance. It appears that a hypothetical advisor preparing for a country mission or a new program officer in an international development organization would not be able to infer with any confidence, from a reading of a country's poverty-reduction strategy, how development assistance for health was being allocated.

FIGURE 8 Health policy and administration as share of total development assistance

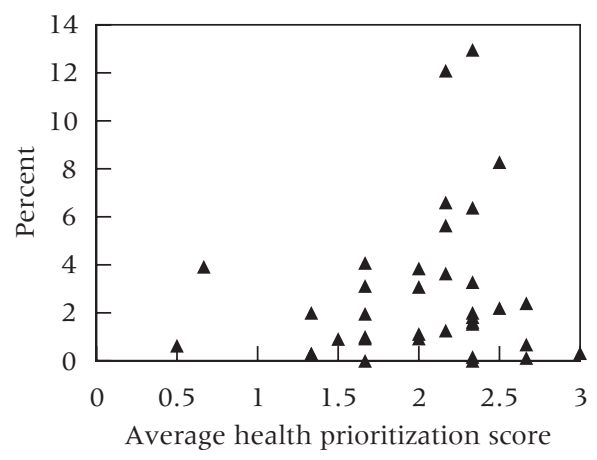

FIGURE 9 Health policy and administration as share of development assistance for health, AIDS, and population

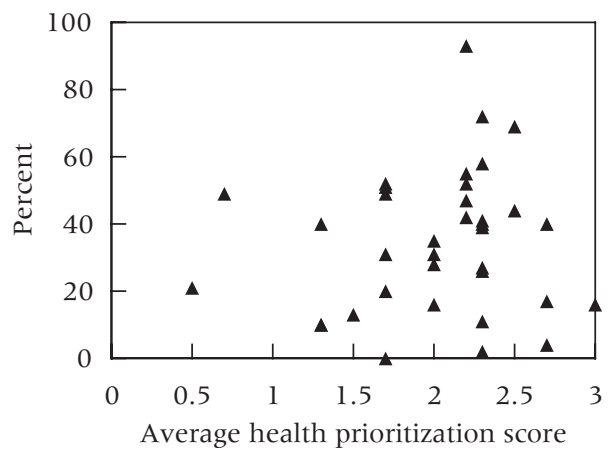

SOURCES: Prioritization scores calculated from information in WHO database (see MacKellar 2005); development assistance shares, Creditor Reporting System. 
This suggests room for improvement in the process of preparing poverty-reduction strategies, in the allocation of official development assistance, or both.

\section{Conclusions}

The gap between needs and resources in global health development is enormous, and, as a result, so is the importance of priority setting. Three questions of relevance to policymakers as they address this challenge are: What are the recent trends in development assistance for the health sector, and what do they tell us about overall priorities in health? What factors explain priorities within the health sector? And how closely do observed development assistance priorities correspond to the health priorities expressed by policymakers in poor countries? In this article I have presented findings related to these questions.

The short answer to the first question is that HIV/AIDS is the priority. It accounts for the increased share of health in total official development assistance over the last decade. If HIV/AIDS is excluded from the calculation, health has actually declined as a share of development assistance, from 5.4 percent in 1993 to 5.0 percent in 2003. Within the health, AIDS, and population sector, apart from HIV/AIDS only infectious disease control has seen an increased share of resources. It is possible that the rising share of infectious disease control, a classic public good, reflects growing reliance on the global public good rationale for international assistance, but other explanations cannot be excluded. Basic health care and infrastructure, health education and personnel development, reproductive health and family planning, and basic nutrition-all pro-poor interventions-have experienced declining shares. Taken together, pro-poor health interventions apart from HIV/AIDS have seen their share of health assistance drop from 57.2 percent to 42.0 percent and their share of total development assistance resources drop from 3.1 percent to 2.8 percent. These trends apply not only to aidrecipient countries as a whole, but to the subset of least-income countries.

The observed declines in share are consistent neither with the current emphasis on health as a priority sector in development, as evidenced by the prominence of health concerns in the Millennium Development Goals, nor with growing awareness of links between health and poverty. The declines lend strength to concerns, voiced by groups such as the WHO Commission on Macroeconomics and Health, regarding the insufficiency of international support for health. They also raise issues about how effectively health assistance is addressing the needs of the poor. Finally, concentrating assistance on HIV/AIDS, however laudable the intent, carries with it the danger of lopsided, distorted health-sector development.

The answer to the second question is that the most commonly cited prioritization tool, the burden of disease as measured in disability-adjusted 
life years, is insufficient to explain observed priorities. Previous research on infectious diseases has concluded that factors apart from the burden of disease play a role in determining how development assistance is allocated. Such factors, it has been argued, include the existence of cost-effective interventions, the characteristics of the victims, the presence of a global advocacy community, the inability of countries to cope on their own, and the possibility of catastrophic national and international consequences if remedial steps are not taken. I have extended and strengthened these assertions by concluding that they apply to all disease categories, not just infectious diseases. HIV/AIDS stands out for the large allocation of resources it receives relative to its contribution to the total burden of disease; so too, though less dramatically, does reproductive and maternal health. Disease categories receiving less support than might be expected on the basis of their contribution to the burden of disease are injuries and nutritional disorders.

These results suggest the need for efforts to devise explicit prioritysetting frameworks in which the burden of disease is only one factor among many. Ongoing work by the Global Forum for Health Research (2004) provides a model for such approaches, although this work is limited to priority setting in health research and development.

In making a first systematic attempt to compare aid allocations to lowincome countries' health priorities as expressed in their poverty-reduction strategies, I have arrived at an ambiguous answer to the third question, namely, if development assistance allocations and country priorities do correspond, the correspondence is not plainly evident. I detected no clear relationship between priorities expressed in poverty-reduction strategies and the composition of development assistance. Methodological problems may be to blame-for example, the index I have devised may not measure priorities per se but rather how well these priorities have been translated into the framework of poverty-reduction strategies. In this case, however, I would expect the index to be related to the share of development assistance allocated to general health policy, administration, and management. I found only slim evidence of this relationship. Whatever the explanation, I conclude that the absence of a clear relationship between how health is treated in the preparation of poverty-reduction strategies and the composition of development assistance should signal to policymakers that there is room for improvement in the process of preparing such strategies, in the allocation of development assistance, or both. 


\section{Notes}

The research resulting in this article was supported by the Development Centre of the Organization for Economic Co-operation and Development; however, the opinions expressed are entirely those of the author. Useful comments by Helmut Reisen and Ulrich Heimenz of the Centre are gratefully acknowledged.

1 For example, following a $\$ 750$ million start-up grant from the Bill and Melinda Gates Foundation, the Global Alliance for Vaccines and Immunization has raised \$577 million in bilateral donor support but only $\$ 5$ million in private non-philanthropy-sector grants (Global Alliance for Vaccines and Immunization 2005). Out of $\$ 35.4$ million disbursed by Roll Back Malaria in 2002, \$25.7 million was financed by traditional donors and $\$ 8.7$ million by WHO (Roll Back Malaria 2003). Out of $\$ 340$ million raised by the International AIDS Vaccine Initiative through the end of 2003, virtually all apart from a $\$ 100$ million start-up grant from the Gates Foundation came from bilateral donors and multilateral institutions (Skolnick et al. 2003). Out of \$5,706 million pledged through 2008 to the Global Fund to Fight AIDS, Tuberculosis, and Malaria, only $\$ 154$ million comes from foundations (again, mostly the Gates Foundation), private firms, and individuals (the Global Fund to Fight AIDS, Tuberculosis, and Malaria 2004). In short, these new actors are simply replicating the existing structure of aid flows.

2 These are the country- and project-level data in the "All details" (5-digit category) database. Available online at «http://wwwl.oecd. org/scripts/cde/members/CRSAuthenticate. asp».

3 If one took account of the fact that many reproductive health and family planning projects contain HIV/AIDS components, the decline in share would be more pronounced.

4 Comprehensive global estimates of disability-adjusted life years by disease category were first prepared by the WHO Global Burden of Disease Project as background research for the 1993 World Development Report (Murray and Lopez 1996). DALYs were proposed, and have been broadly accepted, as one of the most important tools for health policy priority set- ting (World Bank forthcoming 2006). In recent years, WHO produced updated burdenof-disease estimates for 2000, 2001, and 2002 (Mathers et al. 2002). A minor inconvenience is that the regions used by WHO for aggregating country-level DALY estimates are not comparable to the regions used by the Development Assistance Committee. However, the WHO estimates for 2001 have been re-aggregated according to World Bank income regions (which are comparable to Development Assistance Committee regions) by the Disease Control Priorities Project alluded to above. These estimates, to be published next year in the second edition of Disease Control Priorities in Developing Countries (World Bank forthcoming 2006), provide the basis for the discussion in this section. The data have been posted online (with accompanying methodological information) at «http://www.fic.nih.gov/dcpp/gbd. html».

5 A detailed search of project titles, as opposed to 5 -digit CRS codes, would turn up a handful of projects in these areas; however, for practical purposes, we may assume that development assistance directly targeted at noncommunicable diseases and injuries was zero or close to it.

6 The slope of the trend line in Figure 1 is admittedly sensitive to whether my imputation assumption is accurate, especially as it applies to noncommunicable diseases. If development assistance for general health is disproportionately benefiting the well-to-do through public health systems insufficiently attuned to the needs of the poor (an argument made by many), then the trend line might be steeper. This is because the rich live longer and are more likely to suffer from chronic and degenerative conditions; hence, the data point corresponding to noncommunicable diseases would shift vertically upward. However, reallocating general health assistance to noncommunicable diseases would mean reallocating it from other disease conditions. It is likely that HIV/AIDS, which places heavy demands on hospital systems, would still be an outlier on the high side of the new trend line. It is difficult to make similar speculations about other disease conditions. 
7 The targets associated with the healthrelated Millennium Development Goals are to (i) reduce child mortality by two-thirds between 1990 and 2015, (ii) reduce the maternal mortality ratio by three-quarters between 1990 and 2015, (iii) halt and begin to reverse the spread of AIDS by 2015, (iv) halt and begin to reverse the incidence of malaria and other major diseases by 2015. In the area of health, the associated target is to (v) provide, in cooperation with pharmaceutical companies, access to affordable essential drugs in developing countries. General Assembly, A/55/ L.2, 18 September 2000.

8 Available online, together with background documentation, at «http://www.who. int/hdp/database/».

\section{References}

Atkinson, Tony 2003. Innovative Sources for Development Finance-Global Public Economics. Paper prepared for ABCDE-Europe 2003.

Christiansen, K. and Inge Hovland. 2003. "The PRSP initiative: Multilateral policy change and the role of research," Overseas Development Institute Working Paper 216(August). London: ODI.

Development Assistance Committee-UNAIDS. 2004. Analysis of Aid in Support of HIVIAIDS Control, 2000-2002. Paris: OECD.

Devaradjan, Shantayanan, Margaret Miller, and Eric V. Swanson. 2002. "Goals for development: History, prospects, and costs," World Bank Policy Research Working Paper No. 2819. Washington, DC: World Bank. Available online at «http://ssrn.com/abstract=636102».

Global Alliance for Vaccines and Immunization. 2005. "Donors to the Global Alliance for Vaccines and Immunization and The Vaccine Fund," fact sheet published online at "www. vaccinealliance.org".

Global Forum for Health Research. 2004. The 10/90 Report on Health Research 2003-2004. Geneva: Global Forum for Health Research. Available online at "www. globalforum.org».

Global Fund to Fight AIDS, Tuberculosis, and Malaria. 2004. Progress Reports on financial disbursements, resource mobilization, and resource needs, 31 December. Posted online at «http://www.theglobalfund.org/en/about/publications/».

Lomborg, Bjørn (ed.). 2004. Global Crises, Global Solutions. Cambridge: Cambridge University Press.

MacKellar, L. 2005. "Priorities in global assistance for health, AIDS, and population," OECD Development Centre Working Paper No. 244. Paris: OECD.

Maizels, A. and M. K. Nissanke 1984. "Motivations for aid in developing countries," World Development 12(9): 879-900.

Mason, J. B., P. Musgrove, and J.-P. Habicht. 2003. “At least one-third of poor countries' disease burden is due to malnutrition," Disease Control Priorities Project Working Paper No.l Bethesda, MD: Fogarty International Center, National Institutes of Health.

Mathers, Colin D. et al. 2002. Global Burden of Disease 2000: Version 2 Methods and Results. Global Programme on Evidence for Health Policy Discussion Paper No. 50. Geneva: World Health Organization.

Murray, C. and A. Lopez 1996. Global Burden of Disease, 1990. Cambridge, MA: Harvard University Press.

Organization for Economic Co-operation and Development (OECD). 2001. 2000 Development Co-operation Report. Paris: OECD.

Reisen, H. 2004. "Innovative approaches to funding the Millennium Development Goals," OECD Development Centre Policy Brief No. 24. Paris: OECD.

Roberts, John. 2003. "Poverty reduction outcomes in education and health public expenditure and aid," Overseas Development Institute Working Paper 210 (April). London: ODI.

Roll Back Malaria. 2003. Final Report of the External Evaluation of Roll Back Malaria. Published online at «http://www.rbm.who.int/cmc_upload/0/000/015/905/ee_toc.htm». 
Sagasti, Francisco and Keith Bezanson. 2001. "Financing and providing global public goods," Development Financing 2000 Study 2001:2. Stockholm: Swedish Ministry for Foreign Affairs.

Sandler, T. and D. Arce. 2001. "A conceptual framework for understanding global and transnational goods for health," Committee on Macroeconomics and Health Working Paper WG2:1. Geneva: WHO. Available online at «http://www.cmhealth.org/docs/wg2_paperl.pdf».

Shiffman, Jeremy. 2004. Donor Funding Priorities for Communicable Disease Control in Developing Countries. Unpublished working paper, Department of Public Administration, Maxwell School of Public Administration, Syracuse University, Syracuse, New York.

Skolnik, Richard et al. 2003. Independent Evaluation of the International AIDS Vaccine Initiative (IAVI). New York: IAVI.

Stansfield, Sally K., Malayah Harper, Geofrey Lamb, and Julian Lob-Levyt. 2001. "Innovative financing of international public goods for health," Committee for Macroeconomics and Health Working Paper No. WG2:22. Geneva: World Health Organization. Available online at «http://www. cmhealth.org/docs/wg2_paper22.pdf».

United Nations. 2001. "Report of the High Level Panel on Financing for Development." Available online at "http://www.un.org/reports/financing/report_full.htm».

United Nations Development Program. 2003. Human Development Report 2003. New York: UNDP.

World Bank. nd. Getting Serious about Meeting the Millennium Development Goals. Washington, DC: World Bank.

- 2002 (September 18). Better Measuring, Monitoring, and Managing for Development Results. Washington, DC: World Bank.

— 2003 (13 September). "Supporting sound policies with adequate and appropriate financing," report prepared for the Sept. 22, 2003 meeting of the Development Committee. Document No. DC2003-0016. Washington, DC: World Bank 2006. Disease Control Priorities in Developing Countries. Second edition. Forthcoming

World Health Organization Commission on Macroeconomics and Health (Jeffrey D. Sachs, Chair). 2001. Macroeconomics and Health: Investing in Health For Economic Development. WHO: Geneva. 